\title{
Association of intima-media thickening of carotid artery with genetic polymorphisms of the regulator of G-protein signaling 2 gene in patients with hypertension and in the general population
}

\author{
Kei Kamide ${ }^{1,3,5}$, Yoshihiro Kokubo ${ }^{2}$, Jin Yang ${ }^{3}$, Shin Takiuchi ${ }^{4}$, Takeshi Horio ${ }^{1}$, Sachiko Matsumoto ${ }^{3}$, \\ Mariko Banno $^{3}$, Tetsutaro Matayoshi ${ }^{1}$, Hisayo Yasuda ${ }^{1}$, Yoshikazu Miwa ${ }^{1}$, Fumiki Yoshihara ${ }^{1}$, \\ Satoko Nakamura ${ }^{1}$, Hajime Nakahama ${ }^{1}$, Yoshio Iwashima ${ }^{1}$, Ryousuke Oguro ${ }^{1,5}$, Mitsuru Ohishi ${ }^{5}$, \\ Hiromi Rakugi ${ }^{5}$, Tomonori Okamura ${ }^{2}$, Toshiyuki Miyata ${ }^{3}$ and Yuhei Kawano ${ }^{1}$
}

Regulator of G-protein signaling 2 (RGS2) is a key molecule in signal pathways of vasoactive peptides, such as angiotensin II and endothelin 1, and is believed to have an important role in the pathophysiology of atherosclerosis. We have previously reported that common polymorphisms of RGS2 are associated with hypertension in Japanese. In this study, we studied whether the three previously identified common polymorphisms of RGS2 (-638A $>$ G, 1026T $>A$ and 1891-1892delTC) could be implicated in carotid atherosclerosis in Japanese patients with hypertension (459 men and 382 woman) and in a Japanese general population (814 men and 956 woman). We assessed two criteria for carotid atherosclerosis: maximal intima-media thickness (M-IMT) and mean-IMT. When subjects with atherosclerotic lesions were defined as having mean-IMT $\geq 1.0 \mathrm{~mm}$, multivariate logistic regression analysis performed after adjusting for confounding factors showed a significant association of the three common polymorphisms, $-638 \mathrm{~A}>\mathrm{G}$ (AA versus $A G+\mathrm{GG}$ : odds ratio (OR), $1.55 ; 95 \%$ confidence interval $(\mathrm{Cl})$, $1.105-2.185 ; P=0.0113$ only for the general population), $1026 \mathrm{~T}>\mathrm{A}$ (TT versus $\mathrm{TA}+\mathrm{AA}: \mathrm{OR}, 1.42 ; 95 \% \mathrm{Cl}, 1.027-1.972$; $P=0.034$ for hypertensive subjects and $\mathrm{OR}, 1.56 ; 95 \% \mathrm{Cl}, 1.129-2.151 ; \boldsymbol{P}=0.0071$ for the general population), and 1891-1892delTC (II versus ID+DD: OR, $1.44 ; 95 \% \mathrm{Cl}, 1.043-2.008 ; P=0.028$ for hypertensive subjects, OR, $1.32 ; 95 \%$ Cl 1.002-1.742; $P=0.048$ for the total general population and OR $1.59 ; 95 \% \mathrm{Cl} 1.155-2.207 ; P=0.0047$ for the general population), with carotid atherosclerosis. When atherosclerosis was defined as M-IMT $\geqslant 1.0 \mathrm{~mm}$, the values of M-IMT were also significantly different between the three genotypes in the three common polymorphisms. Taken together, these data suggest that genetic polymorphisms in RGS2 are associated with intima-media thickening of carotid artery in humans. Hypertension Research (2011) 34, 740-746; doi:10.1038/hr.2011.25; published online 31 March 2011

Keywords: intima-media thickening of carotid artery; RGS2; single nucleotide polymorphisms

\section{INTRODUCTION}

Normal cardiovascular development and physiology depend in part upon signaling through G-protein-coupled receptors, many of which are coupled to Gq, such as the angiotension II (Ang II) type 1 receptor, sphingosine 1-phosphate receptor and endothelin-1 (ET-1) receptor. Because regulator of G-protein signaling 2 (RGS2) protein functions as a guanosine triphosphatase-activating protein selectively for the $\mathrm{Gq}$ subunit of heterotrimeric G-proteins, it has emerged as a potentially critical regulator of cardiovascular function. ${ }^{1}$

Recent in vitro and in vivo studies have demonstrated that RGS2 is involved in the regulation of blood pressure via its guanosine triphosphatase-activating protein activity on $\mathrm{Gq}$, the signaling mediator common to Ang II and other physiological vasoconstrictors, initiated by G-protein-coupled receptors-dependent or non-G-protein-coupled receptors-dependent pathways. RGS2 is regulated by Ang II and nitric oxide, two important factors for regulating vascular tone. Ang II stimulates the expression of the RGS2 gene, ${ }^{2}$ which in turn might inactivate this pathway via its guanosine triphosphataseactivating protein activity on $\mathrm{Gq}$ and regulate the effect of Ang II. By cyclic guanosine monophosphate-dependent way, nitric oxide activates RGS2, which increases its guanosine triphosphatase-activating protein activity on $\mathrm{Gq}$ and results in vasodilatation. ${ }^{3}$ In RGS2

${ }^{1}$ Division of Hypertension and Nephrology, National Cerebral and Cardiovascular Center, Suita, Osaka, Japan; ${ }^{2}$ Preventive Cardiology, National Cerebral and Cardiovascular Center, Suita, Osaka, Japan; ${ }^{3}$ Research Institute, National Cerebral and Cardiovascular Center, Suita, Osaka, Japan; ${ }^{4}$ Department of Cardiology, Higashitakarazuka Sato Hospital, Osaka University Graduate School of Medicine, Osaka, Japan and ${ }^{5}$ Department of Geriatric Medicine and Nephrology, Osaka University Graduate School of Medicine, Osaka, Japan

Correspondence: Dr K Kamide, Department of Geriatric Medicine, Osaka University Graduate School of Medicine, 2-2 Yamadaoka, Suita, Osaka 565-0871, Japan. E-mail: kamide@geriat.med.osaka-u.ac.jp

Received 24 September 2010; revised 12 December 2010; accepted 11 January 2011; published online 31 March 2011 
knockout mice, the two pathways are disrupted and a strong hypertensive phenotype is observed. ${ }^{3-5}$ In addition, our group and Riddle's group have recently reported that polymorphisms of human RGS2 are associated with human hypertension in a Japanese general population and in American blacks. ${ }^{6,7}$ Just recently, other Japanese group reported that the polymorphism of near RGS2 is also associated with the development of hypertension evaluated by home blood pressure measuring. ${ }^{8}$ These findings suggest that RGS2 is involved in the pathogenesis of human cardiovascular diseases.

Atherosclerosis is a chronic inflammatory disease initiated and perpetuated by a variety of cardiovascular risk factors, including hypertension. ${ }^{9}$ Many ligands for Gq-protein-coupled receptors, such as Ang II, ${ }^{10}$ ET- $1^{11}$ and sphingosine 1 -phosphate, ${ }^{12}$ are involved in the pathogenesis of atherosclerosis. RGS2 has also been reported to participate in the regulation of the signaling pathway of ET-1 ${ }^{13,14}$ and sphingosine 1-phosphate $\mathrm{e}^{15}$ in the cardiovascular system. In addition, nitric oxide has demonstrated beneficial effects in atherosclerosis. ${ }^{16}$ Therefore, pro-atherosclerotic effects could be expected when the regulation by RGS2 of the signaling pathways of these factors is disrupted.

By screening the promoter and exon regions of RGS2 for genetic variations in Japanese patients with hypertension, we found five common single nucleotide polymorphisms (SNPs) with a minor allele frequency greater than $10 \%(-638 \mathrm{~A}>\mathrm{G},-395 \mathrm{G}>\mathrm{C},-161 \mathrm{G}>\mathrm{T}$, $1026 \mathrm{~T}>\mathrm{A}$ and 1891-1892delTC), four of which $(-638 \mathrm{~A}>\mathrm{G}$, $-395 \mathrm{G}>\mathrm{C}, 1026 \mathrm{~T}>\mathrm{A}$ and 1891-1892delTC) were in tight linkage disequilibrium with an r-square of greater than $0.5 .^{6}$ Finally, we successfully performed genotyping of three common SNPs $(-638 \mathrm{~A}>\mathrm{G}, 1026 \mathrm{~T}>\mathrm{A}$ and 1891-1892delTC) in the Japanese general population and found that $1026 \mathrm{~T}>\mathrm{A}$ and 1891-1892delTC are significantly associated with hypertension. In the present study, we examined whether the three common SNPs are associated with atherosclerosis evaluated by intima-media thickening (IMT) of the carotid artery examined by ultrasonography as in two groups of study subjects: patients with hypertension and members of the general population in Japan.

\section{METHODS}

\section{Subjects and DNA samples}

A cohort of patients with hypertension and members of the general population, subjects of the so-called 'Suita Study', were initially the subjects of the present study. The characteristics of subjects with hypertension and the members of the general population have been described previously. ${ }^{6,17,18}$ Briefly, the subjects with hypertension were 953 patients with hypertension (522 men and 431 woman, average age; $65.1 \pm 10.5$ years) recruited from the Division of Hypertension and Nephrology at the National Cardiovascular Center. In all, 92\% of subjects (880 subjects) had essential hypertension, and the remaining $8 \%$ had secondary hypertension. The criteria for hypertension were a systolic blood pressure (SBP) greater than $140 \mathrm{~mm} \mathrm{Hg}$ or a diastolic blood pressure (DBP) greater than $90 \mathrm{~mm} \mathrm{Hg}$ or both, or the use of anti-hypertensive agents. The subjects from the general population were persons who had visited the National Cardiovascular Center every 2 years for general health checkups. Age, SBP, DBP, body mass index (BMI), percentage of current smokers, percentage of current drinkers and prevalence of hypertension and diabetes mellitus were significantly higher in men than in women. Total cholesterol, high-density lipoprotein cholesterol and percentage of hyperlipidemia were significantly higher in women than in men. For both the populations, in addition to performing a routine blood examination that included lipid profiles, glucose levels, blood pressure and anthropometric measurements, a physician or nurse administered questionnaires covering the personal history of cardiovascular diseases, including angina pectoris, myocardial infarction and stroke. Smoking was defined as current smoking. All subjects were Japanese. Because of a lack of clinical data or unsuccessful sequencing and genotyping, 841 patients with hypertension (459 men and 382 women) and 1770 subjects from the general population (814 men and 956 women) were analyzed in present study.

DNA samples were obtained with written informed consent that was approved by the Ethical Review Committee of the National Cardiovascular Center. Genomic DNA was isolated from peripheral blood leukocytes, with an NA-3000 nucleic acid isolation system (Kurabo, Osaka, Japan). ${ }^{19}$

\section{Sequencing and genotyping of SNPs in RGS2}

Sequencing and genotyping have been described previously. ${ }^{6}$ Briefly, we attempted to sequence the promoter region and all exons of RGS2 in 953 Japanese patients with hypertension. All exons with their flanking sequences and approximately $1.6 \mathrm{~kb}$ of the promoter region were directly sequenced with an ABI PRISM 3700 DNA analyzer (Applied Biosystems, Foster City, CA, USA) using seven sets of primers. Information about the primers and PCR conditions is available on request. The obtained sequences were examined for the presence of variations using sequencer software (Gene Codes, Ann Arbor, MI, USA), followed by visual inspection. The A of the ATG of the initiator Met codon is designated as nucleotide +1 . The nucleotide sequence (GenBank accession ID NT_004671; http://www.ncbi.nlm.nih.gov/genbank/) was used as a reference sequence. We have detected some common SNPs $(-638 \mathrm{~A}>\mathrm{G},-395 \mathrm{G}>\mathrm{C}$, $-161 \mathrm{G}>\mathrm{T}$ and $1026 \mathrm{~T}>\mathrm{A}$ ) and deletion polymorphism (1891-1892delTC), with minor allele frequency $>0.1 .^{6}$ Rest of the SNPs showed low allele frequencies with MAF $<0.1$. Three of these four common SNPs $(-638 \mathrm{~A}>\mathrm{G},-395 \mathrm{G}>\mathrm{C}$ and $1026 \mathrm{~T}>\mathrm{A})$ and 1891-1892delTC were in tight linkage disequilibrium with $r^{2}>0.5$. These $(-638 \mathrm{~A}>\mathrm{G},-395 \mathrm{G}>\mathrm{C}$, 1026T > A, 1891-1892delTC) were consisted of a large haplotype block. Other $\mathrm{SNP},-161 \mathrm{G}>\mathrm{T}$, was detected in direct sequencing in 48 subjects; however, genotyping of this SNP for hypertensive subjects and general population was failed by TaqMan method. Thus, we selected 3SNPs located in promoter region $(-638 \mathrm{~A}>\mathrm{G}$; rs 2746071), intron $1(1026 \mathrm{~T}>\mathrm{A}$; rs 2746073$)$ and intron 3 (1891-1892delTC; rs 34717272) for genotyping in present subjects (hypertensive subjects and general population). Three common SNPs $(-638 \mathrm{~A}>\mathrm{G}$, $1026 \mathrm{~T}>\mathrm{A}$ and 1891-1892delTC) were successfully genotyped in 1770 subjects participating in the large cohort of the Suita Study. The TaqMan PCR method was used for genotyping as previously described. ${ }^{20}$ All clinical data and sequencing and genotyping results were anonymous.

\section{Evaluation of carotid atherosclerosis}

Carotid ultrasonography was used to measure mean intima-media thickness (m-IMT) for the evaluation of atherosclerosis, as previously described. ${ }^{21,22}$ Maximal-IMT (M-IMT) was defined as the maximum thickness of the intima-media, including plaques from the region branching off from the brachiocephalic artery (right) or aorta (left) to the bifurcation of the common carotid artery. We assessed two criteria for carotid atherosclerosis: M-IMT $\geqslant 1.0 \mathrm{~mm}$ and $\mathrm{m}$-IMT $\geqslant 1.0 \mathrm{~mm}$. In the general population, the average age of subjects with M-IMT $\geqslant 1.0 \mathrm{~mm}$ was 68.1 years, which was significantly higher than that of the patients with hypertension who had a M-IMT $<1.0 \mathrm{~mm}(54.6$ years). Because aging strongly influences the development of atherosclerosis, we have analyzed all subjects and younger than 65 years in general population, respectively.

\section{Statistical analysis}

Values are expressed as means \pm s.d. The distribution of patient characteristics and genotypes between groups with M-IMT $\geqslant 1.0 \mathrm{~mm}$ and groups with $\mathrm{M}$-IMT $<1.0 \mathrm{~mm}$ or between groups with $\mathrm{m}$-IMT $\geqslant 1.0 \mathrm{~mm}$, and groups with $\mathrm{m}$-IMT $<1.0 \mathrm{~mm}$ among subjects with hypertension or in the general population was analyzed by Student's $t$-test or $\chi^{2}$-analysis. Differences in variables between genotypes were assessed by Student's $t$-test.

The relationship between genotype and the risk of carotid atherosclerosis was expressed in terms of odds ratios (ORs), adjusted for possible confounding factors, including age, sex, BMI, low-density lipoprotein cholesterol, hemoglobin Alc, SBP, DBP and current smoking. The adjusted ORs are given with the $95 \%$ confidence intervals (CIs). Haplotype estimation was performed by the expectation-maximization algorithm. All analyses were performed with SAS statistical software (release 8.2, SAS Institute, Cary, NC, USA) or JMP statistical software (version 4, SAS Institute). Statistical significance was established at $P<0.05$. 


\section{RESULTS}

\section{Study subjects}

The associational studies between three common SNPs $(-638 \mathrm{~A}>\mathrm{G}$, 1026T $>$ A and 1891-1892delTC) and carotid atherosclerosis were performed in subjects with hypertension, all subjects of the general population and subjects of the general population younger than 65 years. The characteristics of the subjects are shown in Table 1 . There were significant differences between subjects with and without atherosclerosis in some variables, including age and SBP for subjects with hypertension and for two groups of the general population; sex and low-density lipoprotein cholesterol for both the groups of the general population; and DBP and percentage of current smokers for subjects with hypertension and subjects of the general population younger than 65 years.

\section{Association of common polymorphisms with carotid atherosclerosis}

The relationships of genotypes and atherosclerosis are shown in Table 2, when carotid atherosclerosis was defined as M-IMT $\geqslant 1.0$. The $-638 \mathrm{~A}>\mathrm{G}$ polymorphism was significantly associated with carotid atherosclerosis in the two groups of the general population, only with a recessive model $\left(\chi^{2}=4.20, P=0.04\right.$, for the total general population; $\chi^{2}=4.25, P=0.04$, for the general population younger than 65 years). The $1026 \mathrm{~T}>\mathrm{A}$ and 1891-1892delTC were significantly associated with carotid atherosclerosis for subjects with hypertension and the two groups of the general population with a recessive model (1026 T > A: $\chi^{2}=4.20, P=0.04$, for the subject with hypertension; $\chi^{2}=4.21, P=0.04$, for the total general population; $\chi^{2}=5.80, P=0.02$, for the general population younger than 65 years. 1891-1892delTC: $\chi^{2}=3.94, P=0.047$, for the subjects with hypertension; $\chi^{2}=5.14$, $P=0.02$, for the total general population; $\chi^{2}=6.71, P=0.01$, for the general population younger than 65 years). The $1026 \mathrm{~T}>\mathrm{A}$ and $1891-$ 1892delTC were also significantly associated with carotid atherosclerosis, with an additive model only in the general population younger than 65 years $\left(1026 \mathrm{~T}>\mathrm{A}: \chi^{2}=6.39, P=0.04 ; 1891-1892\right.$ delTC: $\chi 2$ $=7.92, P=0.02$ ).

The relationships of genotypes and atherosclerosis are shown in Table 3, when carotid atherosclerosis was defined as m-IMT $\geqslant 1.0$. The $1026 \mathrm{~T}>\mathrm{A}$ and 1891-1892delTC were significantly associated with carotid atherosclerosis in subjects with hypertension with a recessive model $\left(1026 \mathrm{~T}>\mathrm{A}: \chi^{2}=4.53, P=0.03,1891-1892\right.$ delTC: $\chi^{2}=4.15, P=0.04$ ). No polymorphisms were found to be related to atherosclerosis in the general population.

When atherosclerosis was defined as $\mathrm{m}$-IMT $\geqslant 1.0 \mathrm{~mm}$ in subjects with hypertension or atherosclerosis was defined as M-IMT $\geqslant 1.0 \mathrm{~mm}$ in the general population, multivariate logistic regression analysis performed after adjusting for age, sex, BMI, low-density lipoprotein cholesterol, hemoglobin A1c, SBP, DBP and current smoking showed a significant association of the three common polymorphisms, $-638 \mathrm{~A}>\mathrm{G}$ (AA versus AG+GG: OR, 1.55; 95\% CI, 1.11-2.19; $P=0.01$ only for the general population younger than 65 years), $1026 \mathrm{~T}>\mathrm{A}$ (TT versus TA+AA: OR, 1.42; 95\% CI, 1.03-1.97; $P=0.03$ for subjects with hypertension and OR, 1.56 ; $95 \% \mathrm{CI}, 1.13-$ $2.15 ; P=0.007$ for the general population younger than 65 years) and 1891-1892delTC (II versus ID+DD: OR, 1.44; 95\% CI, 1.04-2.01; $P=0.03$ for subjects with hypertension, OR, $1.32 ; 95 \% \mathrm{CI}, 1.00-1.74$; $P=0.048$ for the total general population and OR, 1.59; $95 \% \mathrm{CI}$, $1.16-2.21 ; P=0.005$ for the general population younger than 65 years), with carotid atherosclerosis (Table 4). We also performed comparisons of M-IMT values in three genotypes in these common polymorphisms (Table 5).

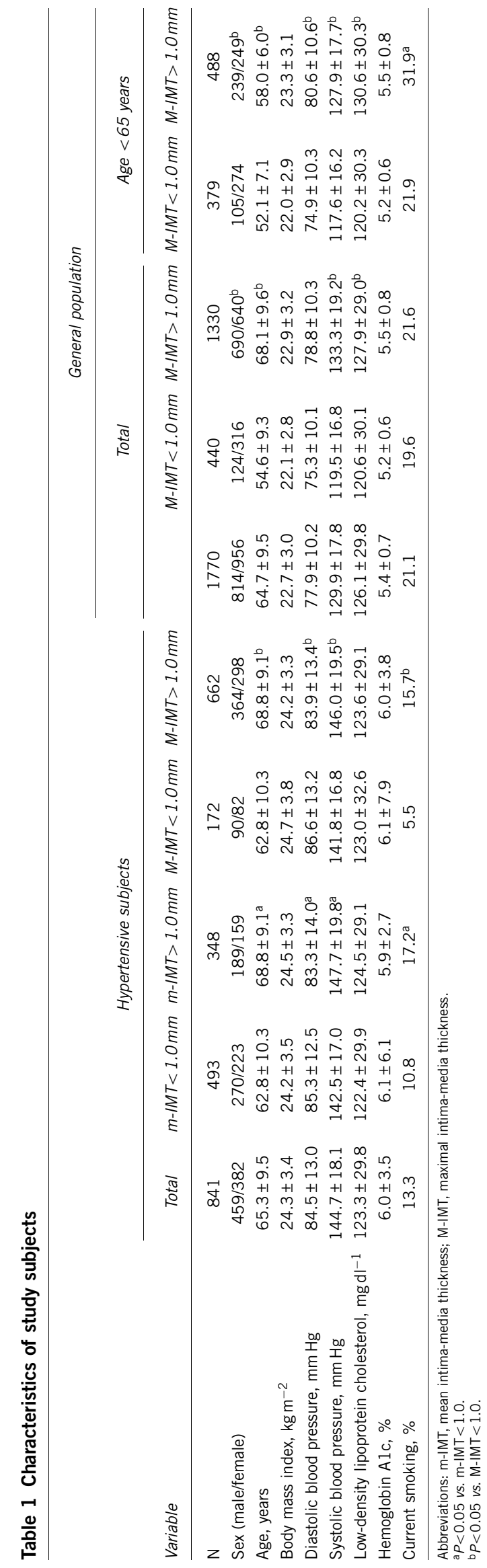


Table 2 Genotype distributions of three common polymorphisms of RGS2 in different sample subjects by M-IMT

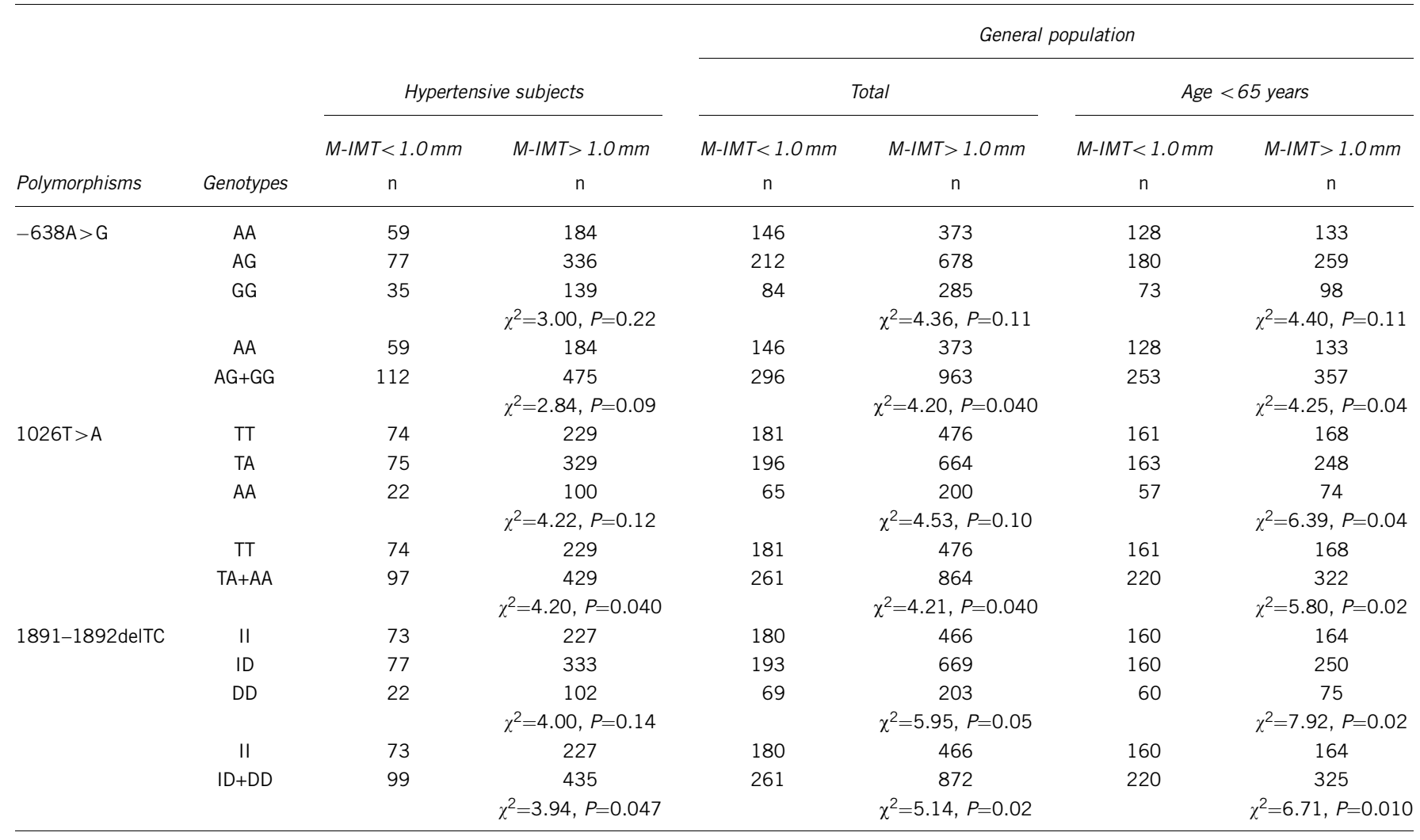

Abbreviation: M-IMT, maximal intima-media thickness.

Table 3 Genotype distributions of three common polymorphisms of RGS2 in different sample subjects by m-IMT

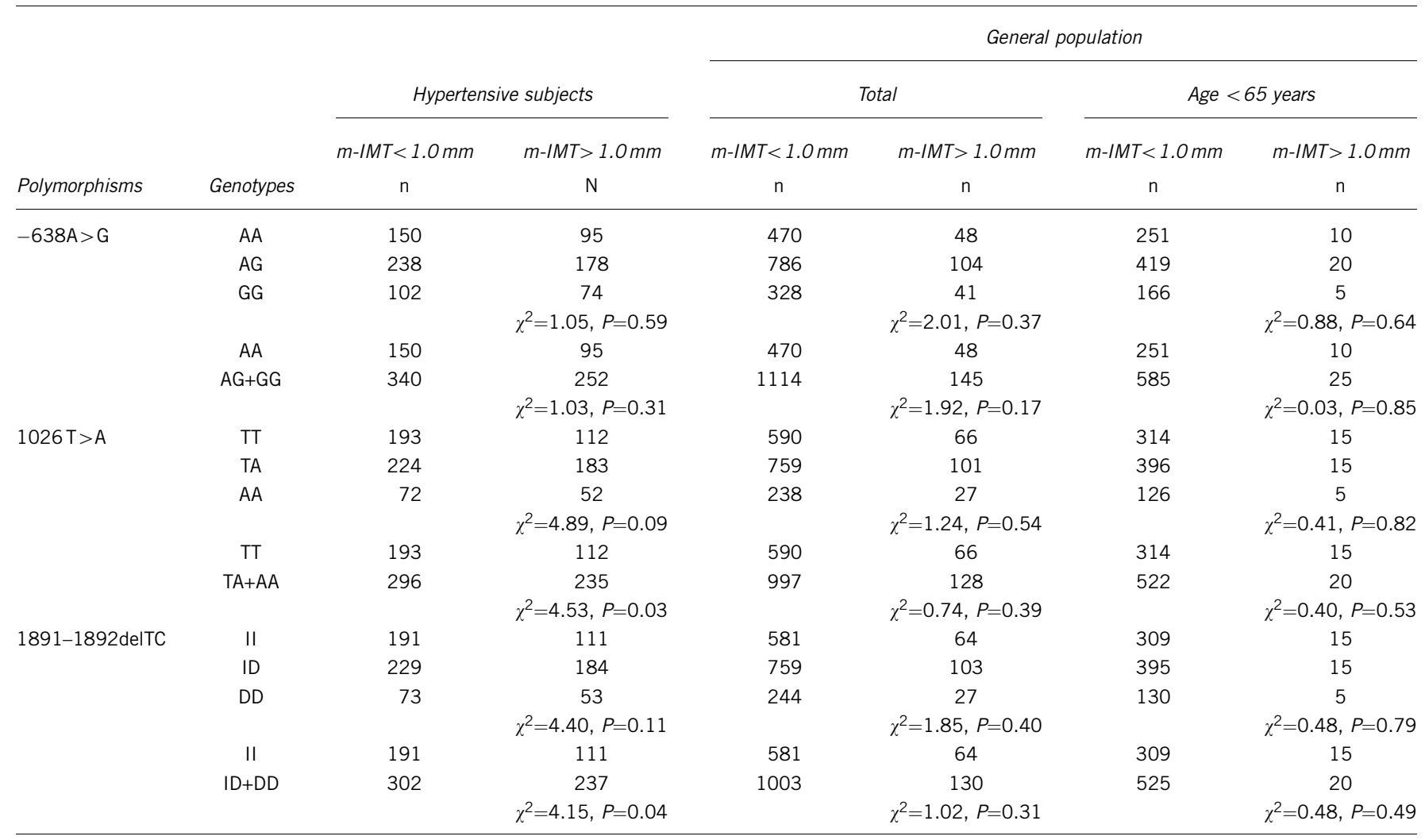

Abbreviation: m-IMT, mean intima-media thickness. 
Table 4 Comparison of atherosclerosis prevalence by genotypes of three polymorphisms of RGS2 in hypertensive subjects and in the general population

\begin{tabular}{|c|c|c|c|c|c|c|c|c|c|}
\hline \multirow[b]{3}{*}{ SNP } & \multirow[b]{3}{*}{ Genotype group } & \multicolumn{4}{|c|}{ The hypertensive subjects } & \multicolumn{4}{|c|}{ The general population } \\
\hline & & \multicolumn{2}{|l|}{$M-I M T$} & \multicolumn{2}{|l|}{$m-I M T$} & \multicolumn{2}{|l|}{ Total } & \multicolumn{2}{|l|}{ Age $<65$ years } \\
\hline & & Odds ratio $(95 \% \mathrm{Cl})$ & $\mathrm{P}^{\mathrm{a}}$ & Odds ratio $(95 \% \mathrm{Cl})$ & $\mathrm{P}^{\mathrm{a}}$ & Odds ratio $(95 \% \mathrm{Cl})$ & $\mathrm{P}^{\mathrm{a}}$ & Odds ratio $(95 \% \mathrm{Cl})$ & $\mathrm{P}^{\mathrm{a}}$ \\
\hline \multirow[t]{2}{*}{$1026 \mathrm{~T}>\mathrm{A}$} & TT & 1 & 0.22 & 1 & 0.03 & 1 & 0.07 & 1 & 0.007 \\
\hline & $\mathrm{TA}+\mathrm{AA}$ & $1.27(0.86-1.87)$ & & $1.42(1.03-1.97)$ & & $1.30(0.98-1.71)$ & & $1.56(1.13-2.15)$ & \\
\hline \multirow[t]{2}{*}{ 1891-1892delTC } & II & 1 & 0.21 & 1 & 0.03 & 1 & 0.048 & 1 & 0.005 \\
\hline & $I D+D D$ & $1.28(0.87-1.81)$ & & $1.44(1.04-2.01)$ & & $1.32(1.00-1.74)$ & & $1.59(1.16-2.21)$ & \\
\hline
\end{tabular}

Abbreviations: $\mathrm{Cl}$, confidence interval; M-IMT, maximal intima-media thickness; m-IMT, mean intima-media thickness.

aMultiple logistic regression analysis, adjusted for age, sex, body mass index, low-density lipoprotein-cholesterol, smoking, hemoglobin Alc, systolic blood pressure and diatolic blood pressure.

Table 5 Comparison of variables for atherosclerosis in hypertensive patients classified by polymorphism in RGS2

\begin{tabular}{|c|c|c|c|c|c|c|c|c|c|c|c|c|c|}
\hline \multirow[b]{2}{*}{ Subjects } & \multirow[b]{2}{*}{ Variables } & \multicolumn{4}{|c|}{$638 A>G$} & \multicolumn{4}{|c|}{$1026 T>A$} & \multicolumn{4}{|c|}{ 1891-1892del TC } \\
\hline & & $A A$ & $A G$ & $G G$ & $\mathrm{P}$ & $T T$ & $T A$ & $A A$ & $\mathrm{P}$ & II & $I D$ & $D D$ & $P$ \\
\hline Hypertensive & m-IMT (mm) & $0.89 \pm 0.20$ & $0.92 \pm 0.23$ & $0.90 \pm 0.21$ & 0.27 & $0.89 \pm 0.20$ & $0.92 \pm 0.23$ & $0.90 \pm 0.21$ & 0.03 & $0.89 \pm 0.20$ & $0.92 \pm 0.23$ & $0.90 \pm 0.21$ & 0.04 \\
\hline Total general & M-IMT (mm) & $1.32 \pm 0.59$ & $1.37 \pm 0.56$ & $1.36 \pm 0.57$ & 0.27 & $1.32 \pm 0.58$ & $1.37 \pm 0.57$ & $1.36 \pm 0.58$ & 0.17 & $1.32 \pm 0.57$ & $1.37 \pm 0.58$ & $1.36 \pm 0.57$ & 0.11 \\
\hline General $<65$ years & M-IMT (mm) & $1.10 \pm 0.41$ & $1.17 \pm 0.48$ & $1.16 \pm 0.46$ & 0.04 & $1.10 \pm 0.39$ & $1.18 \pm 0.49$ & $1.17 \pm 0.48$ & 0.02 & $1.09 \pm 0.39$ & $1.18 \pm 0.49$ & $1.16 \pm 0.47$ & 0.009 \\
\hline
\end{tabular}

There was strong linkage disequilibrium among the three genotyped SNPs in RGS2. The $r^{2}$ values were 0.76 between $-638 \mathrm{~A}>\mathrm{G}$ and $1026 \mathrm{~T}>\mathrm{A}, 0.73$ between $-638 \mathrm{~A}>\mathrm{G}$ and 1891-1892 del TC and 0.98 between and $1026 \mathrm{~T}>\mathrm{A}$ and 1891-1892 del TC. Low frequency haplotypes, namely, those with frequencies below $1 \%$, were excluded from analysis. Table 6 shows the results of logistic regression analysis adjusted by confounding factors for four major haplotypes of 3RGS2 SNPs. H1 had a significant association with M-IMT in total general population and $\mathrm{H} 4$ had also a significant association with M-IMT in general population $<65$-years (Table 6 ). None of other haplotypes show the significant association with IMT.

\section{DISCUSSION}

In the present study, we evaluated the relationship between three common polymorphisms in RGS2 and carotid atherosclerosis evaluated by IMT of carotid artery examined by the ultrasonography using two different populations: patients with hypertension and members of the general population in Japan. Three common polymorphisms (-638A $>\mathrm{G}, 1026 \mathrm{~T}>\mathrm{A}$ and 1891-1892delTC) in RGS2 were associated with carotid atherosclerosis in both subjects with hypertension and members of the general population. These data suggest that genetic variation in RGS2 is involved in atherosclerosis in humans.

We have previously reported that $1026 \mathrm{~T}>\mathrm{A}$ and $1891-1892 \mathrm{delTC}$ in RGS2 are significantly associated with hypertension in the Japanese general population. ${ }^{6}$ In addition, Riddle et al. ${ }^{7}$ have reported in American blacks that, as in our study, 1891-1892delTC is associated with hypertension. Both studies suggest that 1891-1892delTC polymorphism may be important for hypertension in humans. Furthermore, Semplicini et al. ${ }^{23}$ have reported that $1114 \mathrm{C}>\mathrm{G}$ in the $3^{\prime}$ untranslated region of RGS2 is associated with hypertension in
Italian subjects, and that subjects with $\mathrm{G}$ alleles in $1114 \mathrm{C}>\mathrm{G}$ have significantly lower expression of RGS2 mRNA in fibroblasts. Because 1891-1892del TC and $1114 \mathrm{C}>\mathrm{G}$ in $R G S 2$ show a tight linkage disequilibrium $\left(r^{2}=0.78\right), 1891-1892$ del TC or $1114 \mathrm{C}>\mathrm{G}$ in $R G S 2$ is reportedly a SNP greatly increasing the risk of hypertension beyond ethnic differences. In the present study, 1026T $>A$ and 18911892delTC were also significantly associated with carotid atherosclerosis in subjects with hypertension, when atherosclerosis was defined as $\mathrm{m}$-IMT $\geqslant 1.0 \mathrm{~mm}$. In the general population younger than 65 years, all three common polymorphisms were associated with carotid atherosclerosis when atherosclerosis was defined as M-IMT $\geqslant 1.0 \mathrm{~mm}$. Because a significant association was observed by means of multivariate analysis adjusted for confounding factors, combined with the significant difference in the levels of variables for carotid atherosclerosis between different genotype groups of the three common polymorphisms, $-638 \mathrm{~A}>\mathrm{G}, 1026 \mathrm{~T}>\mathrm{A}$ and $1891-1892$ delTC appear to be independent risk factors for atherosclerosis in patients with hypertension or the general population.

It is a very important discussion to assess the influence of high blood pressure on the progression of carotid atherosclerosis. We performed the association of RGS2 SNPs with M-IMT in both nonhypertensive and hypertensive subgroups in general population. There was no significant association of RGS2 SNPs with M-IMT both nonhypertensive and hypertensive subgroups (data were not shown). The reasons are unclear. Although our present results in Table 4 indicated significant association of RGS2 SNPs with carotid atherosclerosis adjusted by confounding factors including blood pressure, the influence of RGS2 SNPs on atherosclerosis may be due to blood pressure elevation, as RGS2 SNPs are associated with hypertension as we reported before. ${ }^{6}$ We are paying attention with the lowest $P$-value in 
the association of RGS2 1891-1892del TC with M-IMT in younger general subjects with age $<65$-years old, which is supposed to be subjects with the strongest influence of genetic backgrounds.

We think that there is a difference between mean $(\mathrm{m})$ and maximal (M)-IMT. The m-IMT might include a combination of different phenotypes including: (1) diffuse medial thickening due to diffuse atherosclerosis; (2) focal lesions; or (3) diffuse medial thickening as a result of hypertensive remodeling or aging. By contrast, the M-IMT might be due to focal lesions of atherosclerosis. We think that m-IMT could be reflecting the influencing aging and chronic vascular wall stress, such as hypertension and M-IMT could be reflecting more atherogenic changes of vascular wall. Genetic backgrounds would be influencing on both m-IMT and M-IMT. Therefore, we think it is reasonable that there is a significant association of RGS2 SNPs with m-IMT in patients with hypertension, and a significant association of RGS2 SNPs with M-IMT in general population even in younger age ( $<65$-years old).

About the cutoff value of IMT in present study, according to the Japanese guidelines for the management of hypertension 2009, the carotid intima-media thickening (IMT) is defined as IMT $>1.0 \mathrm{~mm} .^{24}$ In our study, the actual data of ultrasonography are displayed by one decimal place, for example, $1.0 \mathrm{~mm}$ or $1.1 \mathrm{~mm}$. However, measured raw data of mean-IMT value were sometimes expressed by values with two decimal place such as $1.04 \mathrm{~mm}$. In this case, data were finally handled as IMT value $1.0 \mathrm{~mm}$. Thus, we chose the criteria of IMT $\geqslant 1.0 \mathrm{~mm}$. Furthermore, about the cutoff values of M-IMT, we investigated the association study using two cutoff values of M-IMT, $1.1 \mathrm{~mm}$ and $1.2 \mathrm{~mm}$. In consequence, there was no significant association of RGS2 3 SNPs with M-IMT in both cases of cutoff values, M-IMT $1.1 \mathrm{~mm}$ and $1.2 \mathrm{~mm}$ (data were not shown). We do not know the obvious reasons, however, a quantitative analysis of M-IMT in Table 5 showed the significant differences of M-IMT among genotypes only in general population, age $<65$-years.old, but not in total general population. As genetic influences are supposed to be more sensitive to younger subjects, present results are quite reasonable.

In the present study, we performed genotype analysis of three common polymorphisms; therefore, after the Bonferroni correction for multiple testing was applied, the significance level was $P<0.0167$ $(0.05 / 3$ for three loci). All three common polymorphisms also showed a significant association after the Bonferroni correction with atherosclerosis in the general population younger than 65 years, which is supposed to be subjects with the strongest influence of genetic backgrounds. Both $1026 \mathrm{~T}>\mathrm{A}$ and 1891-1892delTC showed a marginal level $(P=0.034$ and $P=0.028$, respectively). However, genotyped three SNPs were in a same haplotype block and tightly linked each other. Therefore, we can choose one representative SNP from three genotyped SNPs. We think borderline $P$-values would be acceptable in present study.

In the general population, only 1891-1892delTC was significantly associated with atherosclerosis on multivariate analysis. No significant difference in variables for carotid atherosclerosis, including M-IMT, was found between different genotype groups of the three common polymorphisms. This result may be due to the significant difference in the age of subjects between those with M-IMT $\geqslant 1.0 \mathrm{~mm}(68.1 \pm 9.6$ years) and those with M-IMT $<1.0 \mathrm{~mm}$ ( $54.6 \pm 9.3$ years), because aging strongly influences the development of atherosclerosis. Multiple logistic regression analysis did not show a significant association of the polymorphisms to carotid atherosclerosis in subjects with hypertension, when atherosclerosis was defined as M-IMT $\geqslant 1.0 \mathrm{~mm}$; and the genotypes of the three common polymorphisms did not have a significant association with atherosclerosis in the general population, when atherosclerosis was defined as $\mathrm{m}$-IMT $\geq 1.0 \mathrm{~mm}$. These results may be due to the small number of subjects with hypertension who 
had M-IMT $<1.0 \mathrm{~mm}$, or of subjects in the general population who had $\mathrm{m}-\mathrm{IMT} \geqslant 1.0 \mathrm{~mm}$ group.

How the three common polymorphisms of RGS2 influence the pathogenesis of atherosclerosis remains unclear. Of these polymorphisms, $-638 \mathrm{~A}>\mathrm{G}$ is in the promoter region, and $1026 \mathrm{~T}>\mathrm{A}$ and 1891-1892delTC are in intron regions. Whether $-638 \mathrm{~A}>\mathrm{G}$ could result in the decrease of RGS2 transcription needs to be clarified. However, 1891-1892delTC is tightly linked with a functional SNP, $1114 \mathrm{C}>\mathrm{G}$ in RGS2. ${ }^{23}$ Because low expression of RGS2 is thought to lead the strong signaling of Ang $\mathrm{II},{ }^{25}$ faster progression of atherosclerosis could occur in subjects with variations of these SNPs of RGS2 linked with a functional SNP. ${ }^{23}$ On the other hand, these common polymorphisms might be just genetic markers. The RGS2 gene is located at chromosome $1 \mathrm{q} 31,{ }^{26}$ around which there exist susceptibility loci for vascular inflammation, ${ }^{27}$ including the genes for E- and $\mathrm{P}$ - selectin, C-reactive protein and interleukin-10. Vascular inflammation has a central role in atherosclerosis. Perhaps, -638 A>G, 1026 $\mathrm{T}>\mathrm{A}$ and 1891-1892delTC are linked to SNPs of these genes and collectively contribute to atherosclerosis. Expanded genotyping and detailed cross-study for candidate genes are necessary.

We also assessed the relationship between common polymorphisms in RGS2 and carotid atherosclerosis by sex in subjects with hypertension, and in the general population. However, we did not obtain a significant result (data not shown). This inconsistency might be due to a lack of statistical power because of the small sample size. Our study had several limitations, including its cross-sectional design; therefore, a long-term prospective study of the relationship between these common polymorphisms and the development of atherosclerosis is necessary.

In summary, we suggest that common genetic variations in RGS2 are associated with the progression of atherosclerosis in Japanese, independent of other risk factors, including hypertension. Because associational studies are not consistently reproducible as a result of false-positive and false-negative results, ${ }^{28}$ the association of RGS2 polymorphisms with atherosclerosis should be re-examined in another population. Further functional analyses of RGS2 mutants are also necessary to clarify the functional defects caused by these genetic findings.

\section{ACKNOWLEDGEMENTS}

We would like to thank Drs Otosaburo Hishikawa, Katsuyuki Kawanishi and Tadashi Fujikawa for their continuous support of our population survey in Suita City. We also thank the members of the Satsuki-Junyukai. This study was supported in part by grants-in-aid from the Program for Promotion of Fundamental Studies in National Institute of Biomedical Innovation of Japan; the Ministry of Health, Labor, and Welfare of Japan; and the Ministry of Education, Culture, Sports, Science, and Technology of Japan.

1 Heximer SP, Srinivasa SP, Bernstein LS, Bernard JL, Linder ME, Hepler JR, Blumer KJ. G protein selectivity is a determinant of RGS2 function. J Biol Chem 1999; 274. 34253-34259.

2 Grant SL, Lassegue B, Griendling KK, Ushio-Fukai M, Lyons PR, Alexander RW. Specific regulation of RGS2 messenger RNA by angiotensin II in cultured vascular smooth muscle cells. Mol Pharmacol 2000; 57: 460-467.

3 Tang KM, Wang GR, Lu P, Karas RH, Aronovitz M, Heximer SP, Kaltenbronn KM, Blumer KJ, Siderovski DP, Zhu Y, Mendelsohn ME. Regulator of G-protein signaling-2 mediates vascular smooth muscle relaxation and blood pressure. Nat Med 2003; 9 . 1506-1512.

4 Heximer SP, Knutsen RH, Sun X, Kaltenbronn KM, Rhee MH, Peng N, Oliveira-dosSantos A, Penninger JM, Muslin AJ, Steinberg TH, Wyss JM, Mecham RP, Blumer KJ. Hypertension and prolonged vasoconstrictor signaling in RGS2-deficient mice. J Clin Invest 2003; 111: 1259.
5 Sun X, Kaltenbronn KM, Steinberg TH, Blumer KJ. RGS2 is a mediator of nitric oxide action on blood pressure and vasoconstrictor signaling. Mol Pharmacol 2005; 67: 631-639.

6 Yang J, Kamide K, Kokubo Y, Takiuchi S, Tanaka C, Banno M, Miwa Y, Yoshii M, Horio T, Okayama A, Tomoike H, Kawano Y, Miyata T. Genetic variations of regulator of G-protein signaling 2 in hypertensive patients and in the general population. J Hypertens 2005; 23: 1497-1505.

7 Riddle EL, Rana BK, Murthy KK, Rao F, Eskin E, O'Connor DT, Insel PA. Polymorphisms and haplotypes of the regulator of $\mathrm{G}$ protein signaling-2 gene in normotensives and hypertensives. Hypertension 2006; 47: 415-420.

8 Watanabe Y, Metoki M, Ohkubo T, Katsuya T, Tabara Y, Kikuya M, Hirose T, Sugimoto K, Asayama K, Inoue R, Hara A, Obara T, Nakura J, Kohara K, Totsune K, Ogihara T, Rakugi $\mathrm{H}$, Miki T, Imai Y. Accumulation of common polymorphisms is associated with development of hypertension: a 12-year follow-up from the Ohasama study. Hypertens Res 2010; 33: 129-134.

9 Ross R. Atherosclerosis-an inflammatory disease. N Engl J Med 1999; 340: 115-126.

10 Grote K, Drexler H, Schieffer B. Renin-angiotensin system and atherosclerosis. Nephrol Dial Transplant 2004; 19: 770-773.

11 Tamirisa P, Frishman WH, Kumar A. Endothelin and endothelin antagonism: roles in cardiovascular health and disease. Am Heart J 1995; 130: 601-610.

12 Watterson K, Sankala H, Milstien S, Spiegel S. Pleiotropic actions of sphingosine-1phosphate. Prog Lipid Res 2003; 42: 344-357.

13 Snabaitis AK, Muntendorf A, Wieland T, Avkiran M. Regulation of the extracellular signal-regulated kinase pathway in adult myocardium: differential roles of $\mathrm{G}(\mathrm{q} / 11), \mathrm{Gi}$ and $\mathrm{G}(12 / 13)$ proteins in signalling by alpha1-adrenergic, endothelin-1 and thrombinsensitive protease-activated receptors. Cell Signal 2005; 17: 655-664.

14 Zhang W, Anger T, Su J, Hao J, Xu X, Zhu M, Gach A, Cui L, Liao R, Mende U. Selective loss of fine tuning of $\mathrm{Gq} / 11$ signaling by RGS2 protein exacerbates cardiomyocyte hypertrophy. J Biol Chem 2006; 281: 5811-5820.

15 Cho H, Harrison K, Schwartz O, Kehrl JH. The aorta and heart differentially express RGS (regulators of G-protein signalling) proteins that selectively regulate sphingosine 1phosphate, angiotensin II and endothelin-1 signalling. Biochem J 2003; 371: 973-980.

16 Napoli C, de Nigris F, Williams-Ignarro S, Pignalosa O, Sica V, Ignarro LJ. Nitric oxide and atherosclerosis: an update. Nitric Oxide 2006; 15: 265-279.

17 Kokubo Y, Tomoike H, Tanaka C, Banno M, Okuda T, Inamoto N, Kamide K, Kawano Y, Miyata T. Association of sixty-one non-synonymous polymorphisms in forty-one hypertension candidate genes with blood pressure variation and hypertension. Hypertens Res 2006; 29: 611-619.

18 Mannami T, Konishi M, Baba S, Nishi N, Terao A. Prevalence of asymptomatic carotid atherosclerotic lesions detected by high-resolution ultrasonography and its relation to cardiovascular risk factors in the general population of a Japanese city: the Suita study. Stroke 1997; 28: 518-525.

19 Okuda T, Fujioka Y, Kamide K, Kawano Y, Goto Y, Yoshimasa Y, Tomoike H, Iwai N, Hanai S, Miyata T. Verification of 525 coding SNPs in 179 hypertension candidate genes in the Japanese population: identification of 159 SNPs in 93 genes. J Hum Genet 2002; 47: 387-394.

20 Tanaka C, Kamide K, Takiuchi S, Miwa Y, Yoshii M, Kawano Y, Miyata T. An alternative fast and convenient genotyping method for the screening of angiotensin converting enzyme gene polymorphisms. Hypertens Res 2003; 26: 301-306.

21 Takiuchi S, Mannami T, Miyata T, Kamide K, Tanaka C, Kokubo Y, Koyama Y, Inamoto $\mathrm{N}$, Katsuya T, Iwai N, Kawano Y, Ogihara T, Tomoike H. Identification of 21 single nucleotide polymorphisms in human hepatocyte growth factor gene and association with blood pressure and carotid atherosclerosis in the Japanese population. Atherosclerosis 2004; 173: 301-307.

22 Mannami T, Baba S, Ogata J. Potential of carotid enlargement as a useful indicator affected by high blood pressure in a large general population of a Japanese city: the Suita study. Stroke 2000; 31: 2958-2965.

23 Semplicini A, Lenzini L, Sartori M, Papparella I, Calo LA, Pagnin E, Strapazzon G, Benna C, Costa R, Avogaro A, Ceolotto G, Pessina AC. Reduced expression of G-protein signaling 2 in hypertensive patients increases calcium mobilization and ERK1/2 phosphorylation induced by angiotensin II. J Hypertens 2006; 24: 1115-1124.

24 Ogihara T, Kikuchi K, Matsuoka H, Fujita T, Higaki J, Horiuchi M, Imai Y, Imaizumi T, Ito S, Iwao H, Kario K, Kawano Y, Kim-Mitsuyama S, Kimura G, Matsubara H, Matsuura H, Naruse M, Saito I, Shimada K, Shimamoto K, Suzuki H, Takishita S, Tanahashi N, Tsuchihashi T, Uchiyama M, Ueda S, Ueshima H, Umemura S, Ishimitsu T, Rakugi H, Japanese Society of Hypertension Committee. The Japanese Society of Hypertension Guidelines for the Management of Hypertension-JSH2009. Hypertens Res 2009; 32: 3-107.

25 Bodenstein J, Sunahara RK, Neubig RR. N-terminal residues control proteasomal degradation of RGS2, RGS4, and RGS5 in human embryonic kidney 293 cells. Mol Pharmacol 2007; 71: 1040-1050.

26 Wu HK, Heng HH, Shi XM, Forsdyke DR, Tsui LC, Mak TW, Minden MD, Siderovski DP. Differential expression of a basic helix-loop-helix phosphoprotein gene, GOS8, in acute leukemia and localization to human chromosome 1q31. Leukemia 1995; 9: 1291-1298.

27 Dupuis J, Larson MG, Vasan RS, Massaro JM, Wilson PW, Lipinska I, Corey D, Vita JA, Keaney Jr JF, Benjamin EJ. Genome scan of systemic biomarkers of vascular inflammation in the Framingham Heart Study: evidence for susceptibility loci on 1q. Atherosclerosis 2005; 182: 307-314.

28 Lohmueller KE, Pearce CL, Pike M, Lander ES, Hirschhorn JN. Meta-analysis of genetic association studies supports a contribution of common variants to susceptibility to common disease. Nat Genet 2003; 33: 177-182. 